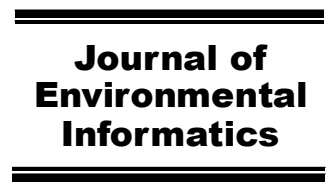

www.iseis.org/jei

\title{
Application of Object Oriented Image Classification and Markov Chain Modeling for Land Use and Land Cover Change Analysis
}

\author{
S. S. Paul ${ }^{1,2}, \mathrm{~J}^{\mathrm{Li}} \mathrm{i}^{1,3^{*}}, \mathrm{R}$. Wheate ${ }^{4}$, and $\mathrm{Y}_{\mathrm{Li}}{ }^{1}$ \\ ${ }^{I}$ WZU-UNBC Joint Research Institute of Ecology and Environment, Wenzhou University (WZU), \\ Wenzhou, Zhejiang Province, P. R. China \\ ${ }^{2}$ Faculty of Land and Food Systems, University of British Columbia (UBC), 2357 Main Mall, Vancouver, BC V6T 1Z4, Canada \\ ${ }^{3}$ Environmental Engineering Program, University of Northern British Columbia (UNBC), Prince George, BC V2N 4Z9, Canada \\ ${ }^{4}$ Geography Program, University of Northern British Columbia (UNBC), Prince George, BC V2N 4Z9, Canada
}

Received 1 May 2015; revised 27 November 2016; accepted 03 December 2016; published online 23 January 2018

\begin{abstract}
Object oriented image classification (OOIC) and neural network aided Markov Chain (MC) modeling tools were used to map and predict land use and land cover (LULC) changes. A case study in the Kiskatinaw River Watershed (KRW) of Canada was presented. With an overall classification accuracy of $90.45 \%$, the multi-temporal Landsat satellite images of KRW were analyzed for 11 selected LULC types. It was found that KRW experienced a significant wetland depletion along with a change in forest cover types from 1984 to 2010. The vulnerability of LULC change in different parts of KRW was predicted through MC modeling based on the obtained transition probability, and the results indicated slight LULC changes from 2010 with a wetland depletion of $67.89 \mathrm{~km}^{2}$. In summary, the proposed methods generated valuable results for informed LULC management and hold the potential to be applied to other watersheds.
\end{abstract}

Keywords: IDRISI selva, land use and land cover (LULC) change, landsat imagery, Markov Chain model, object oriented image classification (OOIC), remote sensing

\section{Introduction}

Effective land use and land cover (LULC) change detection has become a critical worldwide concern in recent years due to varied land use practices under burgeoning population and economic development (Weinzettel et al., 2013; Jia et al., 2015). Remote sensing (RS) technology is a valuable tool for extracting LULC information and generating LULC change inventory. Digital satellite image classification, where image pixels are assigned to real-world LULC feature types, is the most commonly used RS analysis approach for change detection. Conventional per-pixel based image classification (PBC) techniques classify each image pixel individually by considering their spectral information, but they ignore textural and contextual imagery information (Myint et al., 2011; MacLean et al., 2013). However, meaningful interpretation of real-world LULC features requires an evaluation of multiple properties, not just spectral signature. For example, there could be LULC features whose spectral properties are dissimilar, but the shape or neighbourhood relationship are unique providing an opportunity for contextual, textural and shape evaluation in the image

* Corresponding author. Tel.: +1 250960 6397; fax: +1 2509605845.

E-mail address: Jianbing.Li@unbc.ca (J. Li).

SSN: 1726-2135 print/1684-8799 online

(C) 2018 ISEIS All rights reserved. doi:10.3808/jei.201700368 interpretation procedure (Liu et al., 2008; Blaschke et al., 2014). To address such problem, the object oriented image classification (OOIC) has gained popularity and was recognized to be capable of generating less noisy LULC maps as compared to PBC approach (Robertson and King, 2011; Blaschke et al., 2014). It classifies imagery information based on the characteristics of image segments (i.e., a group of spectrally homogeneous pixels), such as segment size, shape, texture, and zonal statistics (Cai et al., 2009a, b; Li et al., 2009, 2011; Blaschke, 2010; Chen et al., 2013; MacLean et al., 2013).

Although many researchers have claimed that OOIC can generate more accurate results for higher-resolution satellite imagery such as QuickBird and IKONOS, OOIC has also been successfully used for satellite imagery with medium resolution (e.g., Landsat Thematic Mapper) (Redoux and Defourny, 2007; Vieira et al., 2012). This is particularly important by noting that Landsat image data have been available since 1972 for every part of the world and can be freely downloaded from U.S. Geological Survey(USGS) data archives and other governmental data sources. Such imagery data are the most effective and easily acquirable source for historical satellite data analysis (Zhang et al., 2011; Hansen and Loveland, 2012). For example, Frohn et al. (2011) used OOIC and Landsat-7 ETM+ imagery for classifying wetlands, and their results illustrated higher accuracy compared to conventional PBC methods. Lyons et al. (2012) also utilized OOIC to analyze Landsat satellite imagery for long-term LULC mapping from $1972 \sim 2010$ in the coastal 
environment of South East Queensland, Australia. In addition to RS analysis, LULC modeling has become a critical component in land use planning and sustainable environmental management. A variety of LULC models has been developed, such as the regressional model and cellular automata mechanistic model (Mas et al., 2014; Verstegen et al., 2014). In general, complex LULC models are capable of generating more robust outputs, but their simulation requires a rigorous and difficult parameterization (Benito et al., 2010). This particularly appears as a significant issue in study areas with limited data availability. A simple LULC model using Markov Chain (MC) might be useful in this regard (Strigul et al., 2012; Tong et al., 2012). The MC model assumes land use at a given time as a discrete state and projects future land use as a function of its previous state (Iacono et al., 2015). It calculates transition matrix for various LULC features based on current driving forces and can predict future LULC change pattern if such driving forces continue (Mas et al., 2014). To obtain the required LULC transition matrix, a multi-layer perception (MLP) neural network algorithm can be used. It can fit complex nonlinear relationship between driving variables and LULC change (Eastman, 2012a, b; Mas et al., 2014), and many studies have reported the robustness of such algorithm in LULC modeling (Almeida et al., 2008; Lin et al., 2011; Fan and Huang, 2012; Mas et al., 2014). The relatively simple and intuitive logic for prediction makes MC modeling an attractive option over more complex and dataintensive stochastic models for land use projections.

One of the significant limitations of the previous MC model based land use projection studies was that they were only based on existing land use maps, aerial photographs or field survey data, and thus the quality of modeling inputs in terms of spatial distribution was greatly restricted. Spatial variation is critical in $\mathrm{MC}$ land use modeling because it produces spatially explicit land use prediction for individual pixels in the raster (e.g., satellite image) and considers spatial heterogeneity in the social and biophysical environments (Verburg et al., 2006). Satellite images with good spatial resolution can provide improved and spatially distributed data inputs for MC modeling, but the integration of satellite image analysis with MC modeling for land use prediction was rarely reported in practice. Moreover, a few research studies combining satellite remote sensing with $\mathrm{MC}$ model used $\mathrm{PBC}$ based classification that has been demonstrated to be less efficient (Mas et al., 2014). For example, Guan et al. (2008) utilized PBC based satellite image classification and MC modeling for land use change prediction in Japan. Revesty (2011) combined the analysis of Landsat satellite image with MC models for a land use modeling case in Iran. Rimal (2011) integrated supervised classification of Landsat data with MC modeling for LULC change analysis in Nepal. This underlines the need to combine OOIC based satellite image analysis with MC modeling to predict future land use changes for number of benefits: (1) better spatial data distribution provided by temporal satellite images, (2) more accurate image classification provided by OOIC technique, (3) last but not the least, enhance the overall predictive capability of $\mathrm{MC}$ models with data input from OOIC derived LULC maps. Therefore, the objective of this study is to present a method that combines OOIC with MC modeling along with an MLP neural network algorithm for LULC change detection and prediction, through a case study in the Kiskatinaw River Watershed (KRW) in Canada. The study watershed is a remote and forested area located in the northeastern part of British Columbia and is marked by the significant insufficiency of spatial data availability. No prior research related to LULC change and modeling within the watershed was reported to date. Taken together, the present study is not only contributing to the improvement of science regarding land use prediction but also providing valuable spatial information to the study watershed for many future studies. Thus, the specific goals of this study are (i) to detect LULC change in KRW from 1984 to 2010 , (ii) to identify the transition probability of various LULC classes based on the current trend of change, and (iii) to predict LULC up to 2020. The Landsat TM and ETM+ satellite images for years 1984, 1999 and 2010 were used for capturing LULC changes and for further analysis. The obtained results can provide a sound basis for informed watershed management in the KRW.

\section{Overview of Study Watershed}

As a densely forested watershed with an area of 2,836 $\mathrm{km}^{2}$, Kiskatinaw River Watershed (KRW) is located in northeastern British Columbia (BC), Canada (Figure 1). It represents a rain-dominated hydrological system with an annual average precipitation of $499 \mathrm{~mm}$, including $320 \mathrm{~mm}$ of rain and 179 mm of snow. The Kiskatinaw river (i.e., the main channel) plays a vital role in northeastern BC's ecosystem. Its average annual flow rate is $10 \mathrm{~m}^{3} / \mathrm{s}$, but the flow can drop to $0.052 \mathrm{~m}^{3} / \mathrm{s}$ in January (DEUS, 2003). KRW has a number of water use values, such as drinking water supply, agriculture, timber harvesting, wildlife, cattle grazing, oil and gas exploration, mineral resources extraction, and recreational parks. In this study, 11 LULC types were identified based on preliminary reconnaissance survey and interviews with relevant stakeholders in KRW. These include cropland (CL), coniferous forest (CF), deciduous forest (DF), mixed forest (MF), planted and regrowth forest (P/RF), forest cut block $(\mathrm{CB})$, forest fire affected land $(\mathrm{FF})$, pasture (PS), waterbody (WT), wetland (WL), and built-up area (BA). KRW is included in the Montney shale gas play which is one of the major shale basins in North America. Recent shale gas exploration and other anthropogenic activities (e.g., removal of trees affected by mountain pine beetles, increasing agricultural and farming activities) have been changing the LULC dynamics in this watershed.

\section{Methods}

\subsection{Data Description}

Both Landsat 4/5 Thematic Mapper (TM) and Landsat 7 Enhanced Thematic Mapper Plus (ETM+) satellite images were employed in this study. The imagery was selected by considering a number of factors, including (a) study objective (i.e., capturing LULC change from early 1980s to 2010), (b) availability of satellite images, (c) quality of images (i.e., cloud free analyzable imagery), and (d) acquisition time of image (i.e., reducing seasonal variability). As a result, three images were 
Table 1. Description of Satellite Images Used in LULC Change Detection

\begin{tabular}{llll}
\hline Date of image & Satellite imagery & Spectral resolution ${ }^{1}$ & Spatial resolution \\
\hline July 17,1984 & Landsat $4 / 5 \mathrm{TM}$ & Band 1 to $5 \& 7$ & $30 \mathrm{~m}$ \\
August 4,1999 & Landsat ETM+ & Band 1 to $5 \& 7$ & $30 \mathrm{~m}$ \\
July 25,2010 & Landsat $4 / 5 \mathrm{TM}$ & Band 1 to $5 \& 7$ & $30 \mathrm{~m}$ \\
\hline
\end{tabular}

${ }^{1}$ Thermal band 6 was excluded from the analysis.

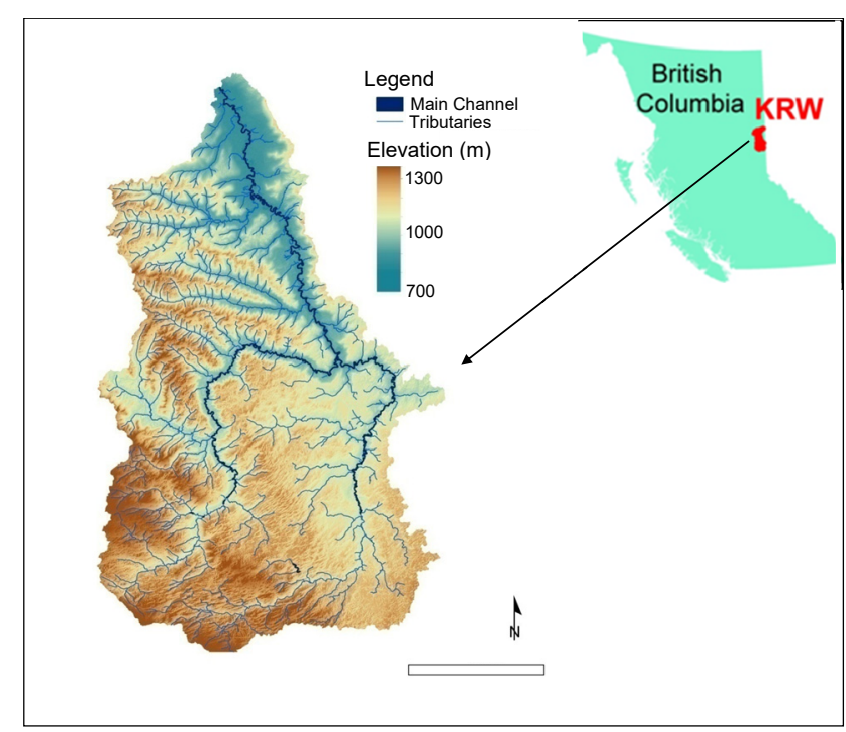

Figure 1. Overview of KRW watershed and its channel network.

selected and downloaded from the data archive at USGS Earth Resources Observation and Science Center (EROS) as indicated in Table 1, including 1984 Landsat 4/5 TM imagery, 1999 Landsat ETM+ imagery, and 2010 Landsat 4/5 TM imagery which represent the early stage of industrial development, the beginning of oil and gas industry booming, and the current land use status in KRW, respectively. In order to keep the analysis free from seasonal variability effects, all of the images were either from late July or early August within a span of $10 \sim 18$ days. Two separate scenes with the path/row of 48/21 and 48/22 were used to cover the entire watershed. The downloaded images were Landsat level $1 \mathrm{~T}$ products which were corrected at the source for radiometric, geometric and precision errors. No additional atmospheric correction was incorporated because this study used single-date images (of each year) for land use classification under which atmospheric correction had minimal effects (Fraser et al., 1977; Kawata et al., 1990; Song et al., 2001). Moreover, the training data for classification were gathered from the respective classified images, and atmospheric correction cannot enhance the classification accuracy in such cases (Song et al., 2001).

\subsection{Image Pre-processing}

Figure 2 presents the framework of image pre-processing and classification that involves the use of several software packages. Pre-processing was mostly performed using PCI Geomatica 10.2, and image analysis was conducted with IDRISI Selva 17.0, while ArcGIS 10.1 and Quantum GIS 1.7 were used

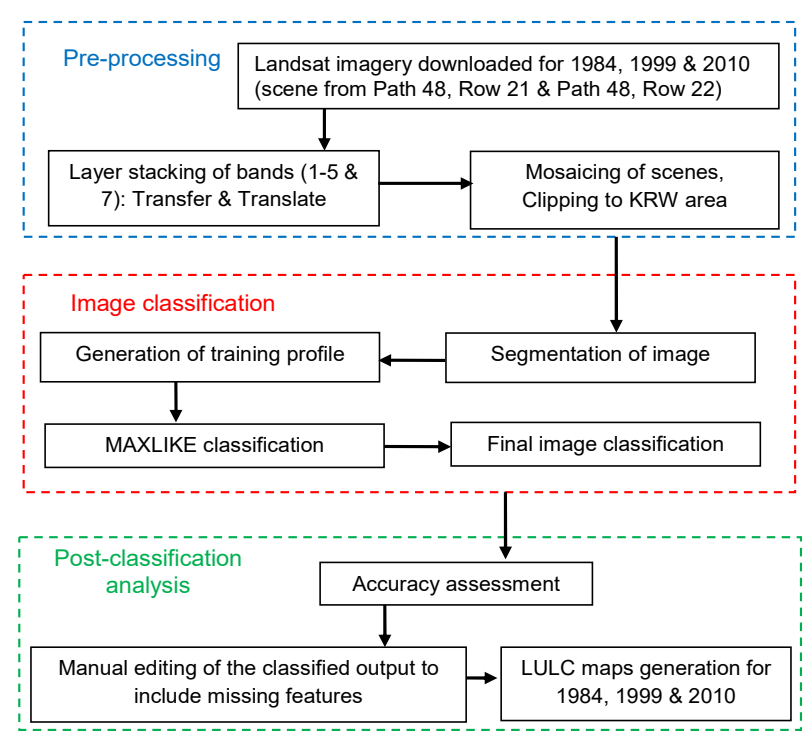

Figure 2. Overview of Landsat image processing and analysis framework.

used at different phases of the analysis and map generation. After image downloading, the individual Landsat bands were stacked sequentially from band 1 to 7 using PCI Geomatica. The two new image scene files were then mosaicked to form a single dataset which was later clipped to the full extent of the study watershed.

\subsection{Object Oriented Image Classification (OOIC)}

OOIC was conducted using the segment classifier in IDRISI Selva 17.0 that consisted of three mutually dependent modules, "SEGMENTATION", "SEGTRAIN" and "SEGCLASS" (Eastman, 2012b). The Landsat bands (1 to $5 \& 7$ ) were segmented using a moving window to generate a variance image. The segmentation process is crucial in OOIC classification since it may generate image objects that are too large or too small and do not represent the actual object of interest on the ground (Blaschke et al., 2014). The study watershed is densely forested and comprises numerous small linear features and cut blocks which attribute to the industrial disturbances (e.g., natural gas development). Therefore, the image segmentation and moving window parameters were required to capture these small-scale disturbances. In general, large similarity tolerance value of the moving window generates larger image objects (Benz et al., 2004; Martha et al., 2011). Various combinations of moving window parameter values were attempted to find the segmentation output that best matches the field situation, and the following parameter values were then obtained and used for segmentation: window width and height of $3 \times 3$, 
weight mean factor of 0.5 , weight variance factor of 0.5 , and similarity tolerance value of 10 . After this step, the "SEGTRAIN" module was used to create a training profile from the sampled training data and a signature file (for each LULC type). A combination of band 5-4-3 (short-wave infrared - near infrared - red bands) was selected for generating RGB composite images. Previous research found that short-wave infrared and infrared bands along with visible band could provide maximum information and color contrast to differentiate LULC features particularly across the diverse forest and agriculture landscape like this study watershed (Lymburner et al., 2000; Cohen and Goward, 2004). In addition, several factors were considered in selecting field sampling locations for creating training profile, including (a) at least 30 sampling polygons for each LULC type, (b) spatial distribution of data polygons, and (c) physical accessibility to sampling locations. The generated training file was used for a supervised classification through the maximum likelihood algorithm in IDRISI. The "SEGCLASS" module was then used to complete the final image classification based on the maximum likelihood output and the segmented image. Such procedures would result in less noisy, smoother and improved classification outputs which were imported into ArcGIS 10.1 for land use map creation. They were also analyzed on IDRISI Selva 17.0 for accuracy assessment, change detection and LULC modeling (Figure 2).

\subsection{Accuracy Assessment}

Accuracy assessment is usually performed either using a new set of field reference data or by comparing with a previously classified reference map for selected sampling points (Olofsson et al., 2014). In this study, accuracy assessment was only conducted using field data of KRW for the image classification output of 2010 because no reference data and LULC maps were available for 1984 and 1999. A stratified random sampling method was used for field reference data collection by dividing KRW into a rectangular matrix of cells with each cell having an area of $25 \mathrm{~km}^{2}$, and this resulted in 113 cells in total. Then, 5 random points were generated within each cell. A minimum of 20 sampling points was selected for each LULC type by randomly adding extra points within the cells when necessary for the LULC types covering a small area (e.g., cropland, water). Each of these points was checked in the field or with higher-resolution satellite imagery where inaccessible. Every match between classified LULC map and reference data was counted as 1 , and the mismatch was counted as 0 . These were then summarized into an error matrix. The overall accuracy (A overall), user's accuracy (Auser), producer's accuracy (A producer), and Kappa coefficient $(K)$ were calculated as follows (Congalton and Green, 2009):

$$
\begin{aligned}
& A_{\text {overall }}=N_{T, \text { correct }} / N_{T} \\
& A_{\text {user }}=N_{L, \text { correct }} / N_{L} \\
& A_{\text {producer }}=N_{R, \text { correct }} / N_{R} \\
& K=(N A-B) /\left(N^{2}-B\right)
\end{aligned}
$$

where $N_{T, \text { correct }}$ and $N_{T}$ represents the total number of samples that were correctly classified and the total number of samples considered for accuracy assessment, respectively; $N_{L \text {,correct }}$ and $N_{L}$ refers to the total number of samples which were correctly classified for a given LULC type (e.g., cropland, coniferous forest) and the total number of samples in that particular LULC type, respectively; $N_{R \text {,correct }}$ and $N_{R}$ represents the total number of samples which were correctly classified for a given LULC type and the total number of samples that were classified to that particular LULC type, respectively; $N$ is the total number of observations included in the error matrix; $A$ is the sum of correct classifications contained in the diagonal elements; and $B$ is the sum of the products of row total and column total for each LULC type in the error matrix (Congalton and Green, 2009).

\subsection{LULC Change Detection and Modeling}

Figure 3 presents the method framework of LULC change detection and modeling. The "Change Analysis" module of Land Change Modeler (LCM) in IDRISI Selva 17.0 was used to evaluate LULC change (i.e., the gain and loss in surface area for each LULC type) between time $T_{1}$ and $T_{2}$. Two separate sets of time period were used, including one from 1984 to 1999 (i.e., $T_{1}=1984$ and $T_{2}=1999$ ) and another from 1999 to 2010 (i.e., $T_{1}=1999$ and $T_{2}=2010$ ). After change analysis, the prediction of LULC in the future time period was conducted using Markov Chain (MC) modeling by assuming that future LULC state $X_{t+1}$ at the time $(t+1)$ depends on the current state $X_{t}$. The transition probability that a cell (i.e., pixel) of LULC type $u_{m}$ alters into LULC type $u_{n}$ from time $t$ to time $(t$ +1 ) was estimated to obtain a transition probability matrix $P$. The LULC state $X_{t+1}$ can then be estimated as follows (Benito et al., 2010):

$X_{t+1}=X_{t} \times P$

where $P$ is a matrix of $m \times m$, and $m$ denotes the number of states (i.e., the number of LULC classes). $P$ between a pair of LULC classes $i$ and $j$ can be stated as:

$\sum_{j=1}^{m} P_{i j}=1 \quad i=1,2,3, \ldots, m$

The LULC transition (i.e., the surface area of LULC change from one type to another) occurred between 1984 and 2010 were calculated by LCM, and the transition maps were then created. Based on these, the future LULC transition was estimated in a matrix using a multi-layer perception (MLP) neural network technique based on a back propagation algorithm. These processes identified a number of transition submodels, each comprising a single LULC transition (e.g., submodel of cropland change to coniferous forest), governed by the same set of driving forces. As shown in Table 2, a set of driving variables which could affect LULC change were identified. The selection of these variables entailed careful consideration of KRW's land use activities and data availability as 
Table 2. Driving Variables Used for LULC Transition Potential Modeling

\begin{tabular}{ll}
\hline \multicolumn{1}{c}{ Driving variable layer } & Role \\
\hline $\begin{array}{l}\text { Distance to gas development } \\
\text { infrastructure }\end{array}$ & $\begin{array}{l}\text { Shale gas development leads to forest clearcutting, road development, high amount of water extraction } \\
\text { from the river, etc. }\end{array}$ \\
$\begin{array}{l}\text { Forest cut blocks planned for } \\
\text { future harvesting }\end{array}$ & $\begin{array}{l}\text { Forestry cut blocks planned and mapped for future harvesting dictates the plantation and regrowth process, } \\
\text { hence the shifting of forest types }\end{array}$ \\
$\begin{array}{l}\text { Cumulative kill by mountain } \\
\text { pine beetle infestation }\end{array}$ & $\begin{array}{l}\text { Active management of mountain pine beetle attack is on action in KRW since its detection in } 2004 \text { which } \\
\text { includes aggressive forest harvesting. This driver comprises the location and number of cumulative kill by } \\
\text { pine beetle infestation }\end{array}$ \\
$\begin{array}{l}\text { Distance to major channel } \\
\text { network }\end{array}$ & $\begin{array}{l}\text { The channel network controls the general hydrology, wetland dynamics, gas development activities, etc. in } \\
\text { this watershed } \\
\text { Digital elevation model } \\
\text { (DEM) and topographic } \\
\text { wetness index (TWI) }\end{array}$ \\
\hline
\end{tabular}

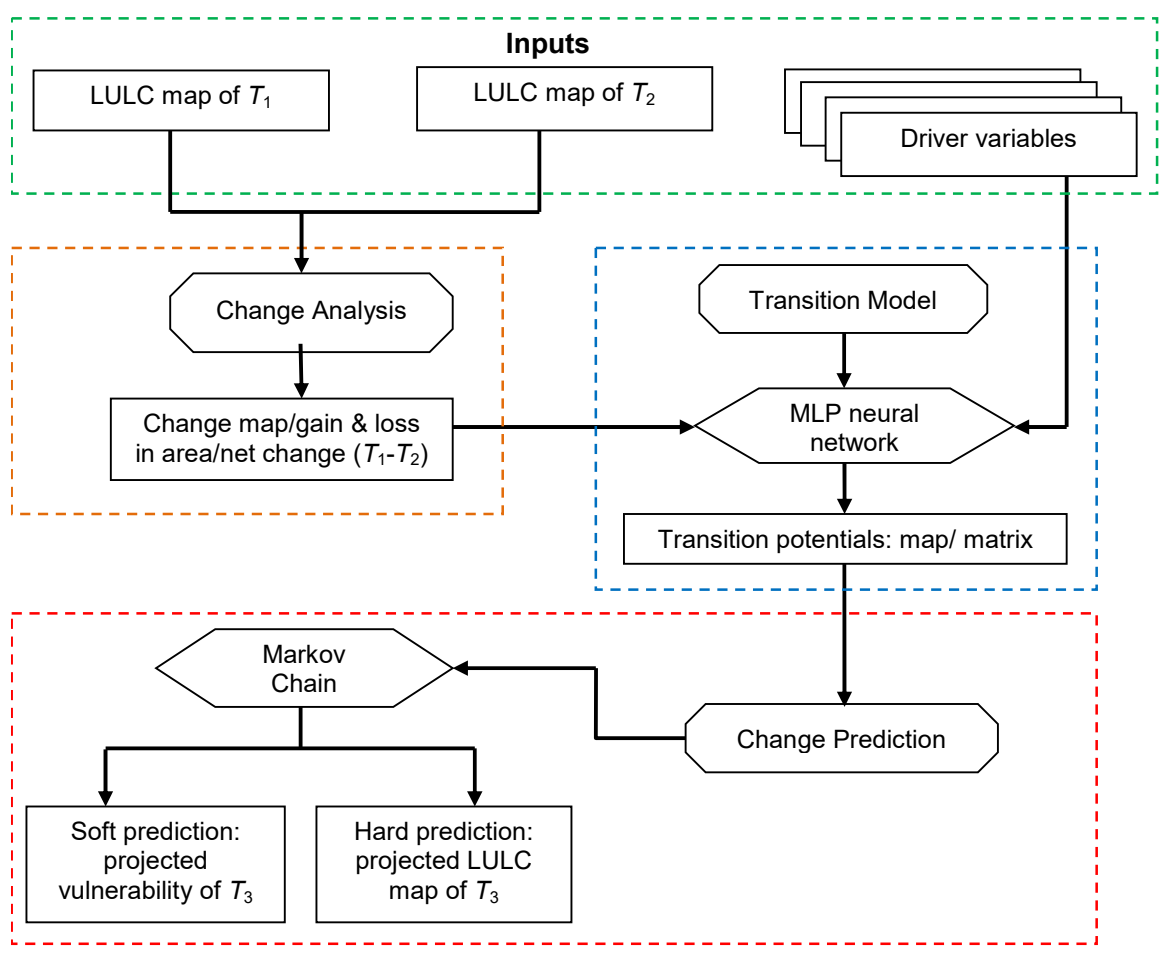

Figure 3. LULC change analysis and modeling framework.

well as reviewing the existing literature. The variables were presented as different GIS layers in the modeling process, and were tested for their effects on modeling accuracy and skill statistics calculated by using the following equations (Eastman, 2012a):

$E_{A}=\frac{1}{T+R}$

$S=\frac{M_{A}-E_{A}}{1-E_{A}}$

where $E_{A}$ is the expected accuracy (\%), T is the number of transition in the sub-model (i.e., $T=1$ since each sub-model comprises only one transition), $R$ is the number of persistent LULC types, $S$ is the measure of model skill (value between -1 to +1 ), and $M_{A}$ is the measured accuracy obtained from MLP analysis. The driving variables which resulted in lower accuracy (i.e., below 50\%) and skill statistics were removed from the analysis, and then the remaining variables were considered to control the transition process for each sub-model. For generating the final transition potential matrix, the MLP analysis implemented a training and validation procedure where it evaluated the accuracy of the model based on a specified set of image pixels (i.e., sample size) that experienced transition from one LULC class to another. In this study, the sample size was set to the smallest number of pixels that faced transition, and $50 \%$ of these samples were used for training and rest were used for validating the model. In the MLP process, it was also attempted to achieve the least root mean square error by changing the model parameters, including the number of hidden layer nodes 


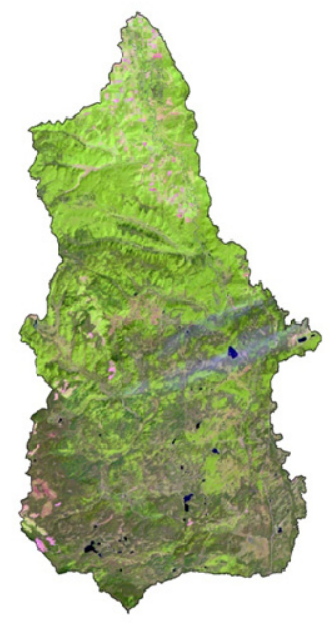

1984

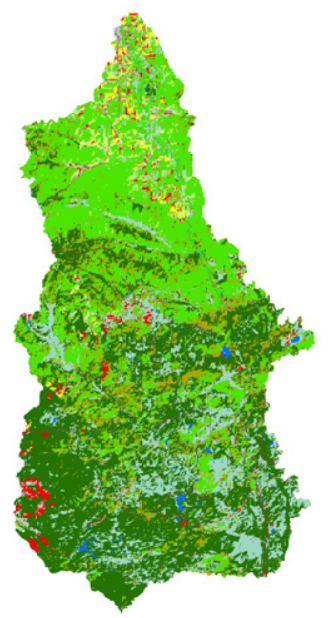

Built-up area

Coniferous forest

Cropland

Cut block

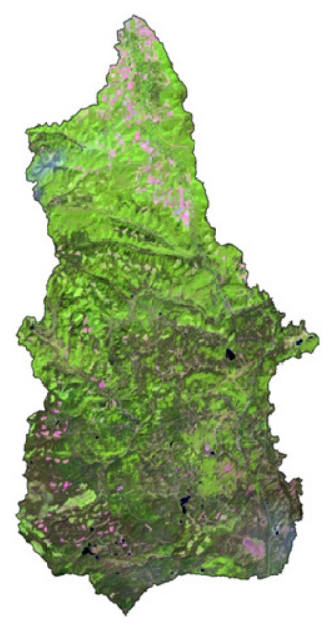

1999

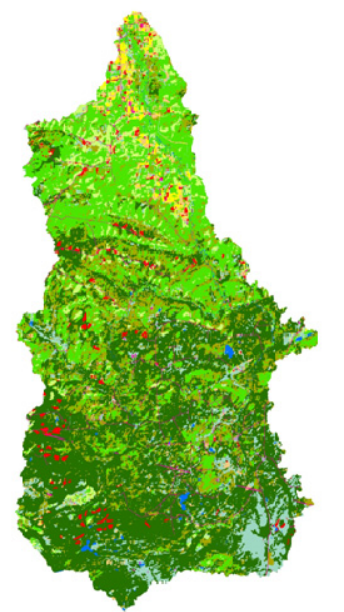

Deciduous forest

Forest fire

Mixed forest

Pasture

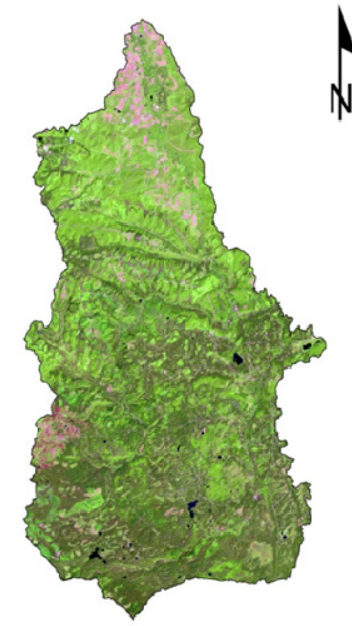

2010

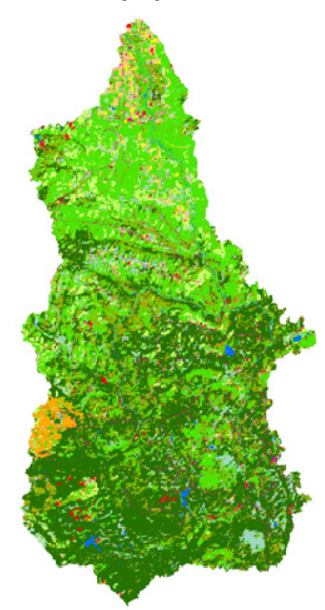

Planted or regrowth

Water

Wetland

$25 \mathrm{~km}$

Figure 4. Landsat images (5-4-3 band combination) (above) and classified LULC maps (below) in KRW for 1984 (left), 1999 (middle) and 2010 (right).

in the neural network. After evaluating each of the sub-models using the aforementioned techniques, MLP generated an accurate estimation of transition potentials in a matrix for the given driving variables.

In the final step of LULC modeling, the transition probabilities estimated from MLP neural network analysis were used in LCM to generate the future LULC scenario in 2020 by using MC modeling. A transition area matrix was obtained through the multiplication of each column in the transition probability matrix by the number of pixels in a corresponding LULC type. It recorded the number of pixels that were expected to convert from one LULC type to another. Based on these transition matrices, the MC model then generated both hard and soft predictions of LULC within KRW. The hard prediction led to a LULC map derived by a multi-objective land allocation algorithm in LCM which considered all of the calculated transitions for cr- eating lists of host classes (i.e., losing land area) and claiming classes (i.e., gaining land area) (Eastman, 2012a). On the other hand, soft prediction identified the vulnerability of LULC change. Vulnerability was defined as the probability of LULC change for a set of transitions. It was calculated based on a method of logical "OR" aggregation by assuming that a location was more vulnerable to LULC change if it was subject to several transitions than if it was only subject to a single transition. The output of logical "OR" aggregation for a pixel is equal to $(a+b-a b)$, where ' $a$ ' represents the probability of that pixel transition to one LULC type and ' $b$ ' represents its transition probability to another LULC type. For example, if a particular pixel has a probability of 0.40 to be changed to one LULC type and 0.30 to another LULC type, the logical "OR" operation would evaluate the LULC change vulnerability as $(0.40+0.30$ $-0.40 \times 0.30=0.58)$. Both predictions were performed for the 
year 2020 .

\section{Results and Discussion}

\subsection{LULC Maps and Image Classification Accuracy}

Figure 4 presents the Landsat images (5-4-3 band combination) of KRW in the three study years and their LULC classification maps, while Table 3 lists the classification accuracy assessment results. It was observed that the dominant LULC types in KRW were forests. The total forest cover including coniferous, deciduous, mixed, and planted or re-growth forest accounted for $79.95,85.59$ and $86.28 \%$ of the watershed in 1984, 1999 and 2010, respectively. It can also be found that the overall accuracy and Kappa coefficient reached $90.45 \%$ and 0.89 , respectively, indicating excellent agreement between classified output and reference data (Monserud and Leemans, 1992). In particular, the producer's and user's accuracy for coniferous forest and water body classification reached $100 \%$ as the spectral signatures of these LULC types were obvious and greatly different from other LULC types. In fact, the coniferous forest appears in dark green and water in dark blue color in the Landsat 5-4-3 composite image. Only three LULC types had a user's accuracy of below $90 \%$, including cropland $(80 \%)$, pasture $(85 \%)$, and wetland $(75 \%)$. This was caused by similar spectral signatures between cropland and pasture as well between wetland and other LULC types partly due to heterogeneity.

Table 3. Accuracy Assessment for the Classification of Landsat Image in 2010

\begin{tabular}{lll}
\hline LULC type & $\begin{array}{l}\text { User's Accuracy } \\
(\%)\end{array}$ & $\begin{array}{l}\text { Producer's Accuracy } \\
(\%)\end{array}$ \\
\hline Cropland & 80.00 & 84.21 \\
Coniferous forest & 100.00 & 100.00 \\
Deciduous forest & 95.00 & 90.48 \\
Mixed forest & 90.00 & 85.71 \\
Planted/regrowth forest & 95.00 & 90.48 \\
Cut block & 90.00 & 85.71 \\
Pasture & 85.00 & 77.27 \\
Water & 100.00 & 100.00 \\
Wetland & 75.00 & 93.75 \\
Built-up area & 90.00 & 94.74 \\
Forest fire & 95.00 & 95.00 \\
\hline
\end{tabular}

Overall Accuracy: 90.45\%; Kappa coefficient: 0.89

\subsection{Analysis of LULC Changes from 1984 to 2010}

Table 4 summarizes the surface area covered by different LULC types in KRW. This forested watershed had a large mature forest cover from 1984 to 2010. Subtle changes were observed for the mature coniferous, deciduous and mixed forest types. The noticeable change of planted or re-growth forest type and cut blocks from 1984 to 2010 indicates the impacts of forestry in this area, although cut blocks in recent images were also attributed to the development of oil and gas industry. Cropland and pasture were hard to differentiate during the image classification process in many cases, but they combinedly showed a considerable change between 1984 and 2010, highlighting the amplified agricultural and farming activities within KRW. An increase of $29.07 \mathrm{~km}^{2}$ of built-up area from 1984 to 2010 is indicative of the industrial boom in this area, particularly shale gas development activity. The forest fire at Hour Glass of KRW (in 2006) affected $33.19 \mathrm{~km}^{2}$ of surface area which was identified as dead and burnt forest patch. The image classification analysis also identified a striking change (i.e., $270.92 \mathrm{~km}^{2}$ ) in wetland, while most of the wetland depletion $\left(233.40 \mathrm{~km}^{2}\right)$ occurred between 1984 and 1999. This significant depletion warrants further investigation to understand the wetland change dynamics. Considering the significance of such wetland depletion and classification accuracy (user accuracy $-75 \%$ ) of the wetland, the analysis method in this study should be revisited for this particular LULC type in future. The combination of multiple data and different training and sampling techniques may produce more accurate output for wetland detection (Zhang et al., 2011).

Figure 5 presents the gain and loss of surface areas for all LULC types in KRW. From 1984 to 1999, there was a high negative change for the deciduous forest (i.e., $-135.86 \mathrm{~km}^{2}$ ) and wetland $\left(-233.40 \mathrm{~km}^{2}\right)$, indicating higher loss than any gain in the surface area for these two LULC types. In contrast, other LULC types had a higher gain than loss, leading to a positive net change of surface area, including cropland $\left(8.43 \mathrm{~km}^{2}\right)$, coniferous forest $\left(116.39 \mathrm{~km}^{2}\right)$, mixed forest $\left(99.60 \mathrm{~km}^{2}\right)$, planted and re-growth forest $\left(80.14 \mathrm{~km}^{2}\right)$, pasture $\left(45.1 \mathrm{~km}^{2}\right)$, and builtup area $\left(21.15 \mathrm{~km}^{2}\right)$. The change of forest types may be attributed to the active forest industrial activities. From 1984 to 1999, the deciduous forest harvesting seemed higher than other forest types. A large increase in planted and re-growth forest indicates that the harvested forest area was recovered by a planned and managed forestry practice in KRW. The increase in cropland, pasture, and built-up area highlights the escalating land use activity. However, during the period from 1999 to 2010, more LULC types were associated with a negative net change of surface area, including cropland $\left(-12.88 \mathrm{~km}^{2}\right)$, coniferous forest $\left(-67.61 \mathrm{~km}^{2}\right)$, mixed forest $\left(-85.69 \mathrm{~km}^{2}\right)$, cut block $\left(-17.08 \mathrm{~km}^{2}\right)$, water body $\left(-0.7 \mathrm{~km}^{2}\right)$, and wetland $\left(-37.52 \mathrm{~km}^{2}\right)$. The negative change of coniferous and mixed forest could be caused by their harvesting. There was a continuing depletion trend of the wetland during this time period although at a slower rate than the period from 1984 to 1999 . Other LULC types exhibited a positive net change of surface area from 1999 to 2010, including deciduous forest $\left(154.55 \mathrm{~km}^{2}\right)$, planted and re-growth forest $\left(17.15 \mathrm{~km}^{2}\right)$, pasture $\left(8.67 \mathrm{~km}^{2}\right)$, built-up area $\left(7.92 \mathrm{~km}^{2}\right)$, and the forest fire affected area $\left(33.19 \mathrm{~km}^{2}\right)$. The increase in deciduous forest confirms that the harvested forest has been restocked. The small but constantly increasing built-up area underscores the ongoing development activities in KRW.

\subsection{Transition Potential and LULC Change Prediction}

Each LULC transition sub-model was evaluated for its combination of governing driving variables. For example, the sub-model of planted or re-growth forest transition to deciduous forest required two governing driving variable layers, including "forest cut blocks planned for future harvesting" and 
Table 4. Surface Area Covered by Each LULC Type in a Particular Year in KRW (Total Study Area: 2,836 km²)

\begin{tabular}{|c|c|c|c|c|c|c|}
\hline \multirow{3}{*}{ LULC type } & \multicolumn{6}{|l|}{ Study year } \\
\hline & \multicolumn{2}{|l|}{1984} & \multicolumn{2}{|l|}{1999} & \multicolumn{2}{|l|}{2010} \\
\hline & Area $\left(\mathrm{km}^{2}\right)$ & Ratio (\%) & Area $\left(\mathrm{km}^{2}\right)$ & Ratio (\%) & Area $\left(\mathrm{km}^{2}\right)$ & Ratio (\%) \\
\hline Cropland (CL) & 23.27 & 0.82 & 31.70 & 1.12 & 18.82 & 0.66 \\
\hline Coniferous forest $(\mathrm{CF})$ & 1059.06 & 37.35 & 1175.45 & 41.44 & 1107.84 & 39.05 \\
\hline Deciduous forest (DF) & 796.65 & 28.09 & 660.79 & 23.30 & 815.34 & 28.83 \\
\hline Mixed forest (MF) & 351.97 & 12.41 & 451.57 & 15.91 & 365.88 & 12.87 \\
\hline Planted/regrowth forest $(\mathrm{P} / \mathrm{RF})$ & 59.94 & 2.10 & 140.08 & 4.94 & 157.23 & 5.53 \\
\hline Cut block (CB) & 44.70 & 1.58 & 43.46 & 1.54 & 26.38 & 0.93 \\
\hline Pasture (PS) & 6.53 & 0.23 & 51.63 & 1.82 & 60.30 & 2.12 \\
\hline Water (WT) & 21.49 & 0.76 & 21.18 & 0.75 & 20.48 & 0.72 \\
\hline Wetland (WL) & 454.22 & 16.02 & 220.82 & 7.79 & 183.30 & 6.45 \\
\hline Built-up area (BA) & 18.17 & 0.64 & 39.32 & 1.39 & 47.24 & 1.67 \\
\hline Forest fire affected land (FF) & 0.00 & 0.00 & 0.00 & 0.00 & 33.19 & 1.17 \\
\hline
\end{tabular}

Table 5. Probability Matrix of LULC Transition from 2010 to 2020

\begin{tabular}{|c|c|c|c|c|c|c|c|c|c|c|}
\hline \multirow{2}{*}{$\begin{array}{l}\text { Given } \\
\text { LULC } \\
\text { type }\end{array}$} & \multicolumn{10}{|c|}{ Probability of transition to $\longrightarrow$} \\
\hline & $\mathrm{CL}$ & $\mathrm{CF}$ & DF & MF & $\mathrm{P} / \mathrm{RF}$ & CB & PS & WT & WL & BA \\
\hline $\mathrm{CL}$ & 0.16 & 0.00 & 0.05 & 0.00 & 0.10 & 0.01 & 0.51 & 0.00 & 0.13 & 0.04 \\
\hline $\mathrm{CF}$ & 0.00 & 0.92 & 0.01 & 0.02 & 0.01 & 0.01 & 0.00 & 0.00 & 0.02 & 0.01 \\
\hline DF & 0.00 & 0.00 & 0.82 & 0.06 & 0.10 & 0.00 & 0.00 & 0.00 & 0.01 & 0.01 \\
\hline MF & 0.00 & 0.19 & 0.14 & 0.54 & 0.03 & 0.02 & 0.01 & 0.00 & 0.06 & 0.01 \\
\hline $\mathrm{P} / \mathrm{RF}$ & 0.04 & 0.00 & 0.33 & 0.00 & 0.40 & 0.00 & 0.10 & 0.00 & 0.13 & 0.00 \\
\hline $\mathrm{CB}$ & 0.04 & 0.04 & 0.05 & 0.37 & 0.06 & 0.02 & 0.13 & 0.00 & 0.26 & 0.03 \\
\hline PS & 0.14 & 0.00 & 0.03 & 0.00 & 0.03 & 0.05 & 0.59 & 0.00 & 0.15 & 0.01 \\
\hline WT & 0.00 & 0.00 & 0.00 & 0.01 & 0.00 & 0.00 & 0.04 & 0.92 & 0.03 & 0.00 \\
\hline WL & 0.00 & 0.23 & 0.14 & 0.30 & 0.00 & 0.00 & 0.02 & 0.00 & 0.31 & 0.00 \\
\hline BA & 0.04 & 0.01 & 0.02 & 0.00 & 0.00 & 0.03 & 0.03 & 0.00 & 0.03 & 0.84 \\
\hline
\end{tabular}
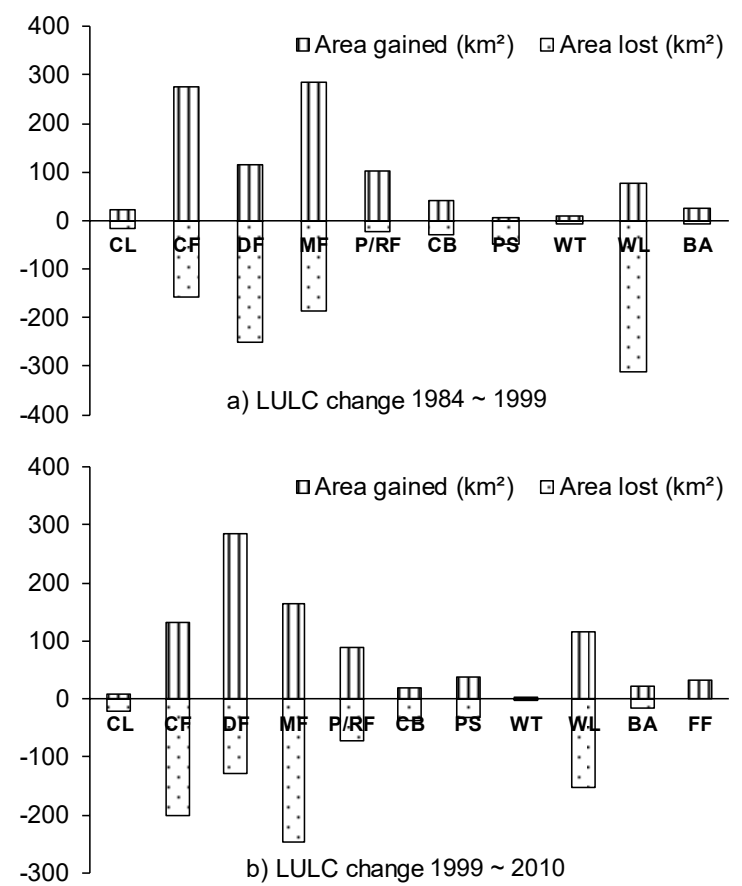

Figure 5. Analysis of LULC change during two periods, (a) $1984 \sim 1999$, (b) $1999 \sim 2010$. "cumulative kill by mountain pine beetle infestation". Four governing driving variables were identified for the sub-model of wetland transition to pasture, including "distance to gas development infrastructure", "distance to major channel network", "topographic wetness index (TWI)", and "digital elevation model (DEM)", with the modeling accuracy and skill measure of $78.55 \%$ and 0.57 , respectively. It should be noted that the performance of LULC transition sub-model was affected by insufficient spatial data for planning, policy and regulatory variables in KRW.

Table 5 lists the LULC transition probability matrix from 2010 to 2020 which was estimated based on the aforementioned transition sub-models (that captured the LULC transitions from 1984 to 1999 and from 1999 to 2010). Coniferous $(0.92)$ and deciduous $(0.82)$ forests showed a high probability of maintaining their current status. However, the mixed forest only had a probability of 0.54 for maintaining its current state, and it could convert to coniferous forest at a probability of 0.19 . The probability of planted or re-growth forest conversion to deciduous forest was 0.33 , while it will remain its current state at a probability of 0.40 . Such probability estimates represent the planned and healthy forestry practices in KRW since no major depleting trend for any forest type is expected. The probability matrix also shows that the transition from cropland to pasture (0.51) and vice-versa (0.14) will be continuing, and 
Table 6. Expected Transition of Pixels from 2010 to 2020

\begin{tabular}{|c|c|c|c|c|c|c|c|c|c|c|}
\hline \multirow{2}{*}{ Pixels in } & \multicolumn{10}{|c|}{ Expected transition to $\rightarrow$} \\
\hline & $\mathrm{CL}$ & $\mathrm{CF}$ & $\mathrm{DF}$ & $\mathrm{MF}$ & $\mathrm{P} / \mathrm{RF}$ & $\mathrm{CB}$ & PS & WT & WL & $\mathrm{BA}$ \\
\hline CL & 20913 & 0 & 0 & 0 & 0 & 0 & 0 & 0 & 0 & 0 \\
\hline $\mathrm{CF}$ & 0 & 1192282 & 4501 & 10791 & 5488 & 7338 & 0 & 0 & 9558 & 3453 \\
\hline DF & 0 & 0 & 831158 & 28544 & 43795 & 0 & 0 & 0 & 3960 & 3141 \\
\hline MF & 0 & 38905 & 29027 & 319499 & 6464 & 0 & 0 & 0 & 12602 & 0 \\
\hline $\mathrm{P} / \mathrm{RF}$ & 0 & 0 & 29036 & 0 & 145759 & 0 & 0 & 0 & 0 & 0 \\
\hline $\mathrm{CB}$ & 0 & 0 & 0 & 0 & 0 & 29312 & 0 & 0 & 0 & 0 \\
\hline PS & 0 & 0 & 0 & 0 & 0 & 0 & 66995 & 0 & 0 & 0 \\
\hline WT & 0 & 0 & 0 & 0 & 0 & 0 & 0 & 15051 & 0 & 0 \\
\hline WL & 0 & 22838 & 14210 & 30223 & 0 & 0 & 2068 & 0 & 134392 & 0 \\
\hline BA & 0 & 0 & 0 & 0 & 0 & 0 & 0 & 0 & 0 & 52499 \\
\hline
\end{tabular}

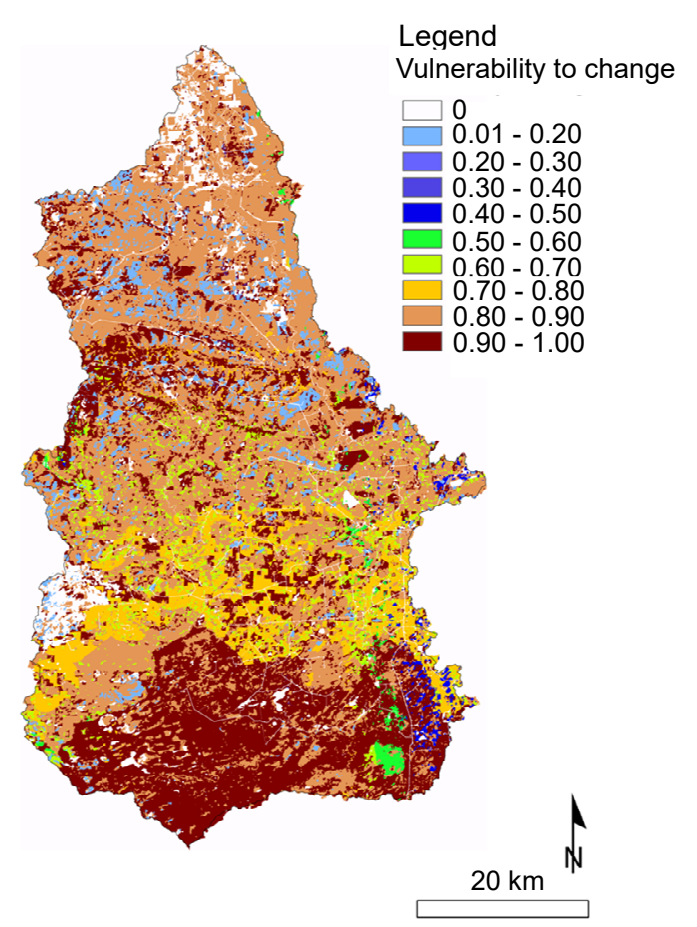

Figure 6. Vulnerability to LULC change in KRW from 2010 to 2020 .

Table 7. Surface Areas of LULC Types Obtained from Hard Predictions

\begin{tabular}{lllll}
\hline \multirow{2}{*}{$\begin{array}{l}\text { LULC } \\
\text { type }\end{array}$} & 2010 & \multicolumn{3}{l}{2020} \\
\cline { 2 - 5 } Area $\left(\mathrm{km}^{2}\right)$ & Ratio $(\%)$ & Area $\left(\mathrm{km}^{2}\right)$ & Ratio $(\%)$ \\
\hline CL & 18.82 & 0.66 & 18.82 & 0.66 \\
CF & 1107.84 & 39.06 & 1164.88 & 41.08 \\
DF & 815.34 & 28.75 & 800.01 & 28.21 \\
MF & 365.88 & 12.90 & 324.51 & 11.44 \\
P/RF & 157.23 & 5.55 & 201.88 & 7.12 \\
CB & 26.38 & 0.93 & 34.13 & 1.21 \\
PS & 60.30 & 2.13 & 63.57 & 2.24 \\
WT & 20.48 & 0.72 & 20.79 & 0.73 \\
WL & 183.30 & 6.46 & 115.41 & 4.07 \\
BA & 47.24 & 1.67 & 58.81 & 2.07 \\
FF & 33.19 & 1.17 & 33.19 & 1.17 \\
\hline
\end{tabular}

there is a probability of 0.92 that the open water bodies will not change. It can be found from Table 5 that wetland to forest conversion will remain active, with the probability of 0.23 for transition to coniferous forest, 0.14 for transition to deciduous forest, and 0.30 to mixed forest, respectively. There is only a probability of 0.31 that wetland extent will be unaffected, although there is a noticeable likelihood of alteration of other LULC types to wetland, such as the transition from cropland to wetland (0.13), from planted or re-growth forest to wetland (0.13), from cut block to wetland (0.26), and from pasture to wetland (0.15).

A transition area matrix (Table 6) was obtained based on the transition probability matrix, and the soft and hard prediction maps were then produced. Figure 6 presents the soft prediction output as a vulnerability map of LULC change from 2010 to 2020 . Figure 7 presents the hard prediction as the LULC map of 2020, with forest fire affected area in 2010 LULC map being excluded from the transition modeling process. The soft prediction provides a more comprehensive assessment of LULC change potential by illustrating the areas with varying degree of vulnerability. It can be found that most of the southern portion of KRW is highly vulnerable to LULC change in 2020. This is reasonable because this part of the watershed has a large area of wetland which has exhibited the most significant depletion in the past years. The considerable vulnerability was also observed in the northern portion of KRW where the continuing intensified oil and gas development along with increased agricultural and farming activities are expected. The middle portion of KRW is characterized by mixed vulnerability to change while most of the open water body showed nearly no vulnerability to change.

Table 7 lists the surface areas of LULC types in 2010, and 2020 calculated from the hard predictions (Figure 7). Only slight LULC changes for these years were expected. For example, forest cover will experience minor changes with a surface area increase of $45 \mathrm{~km}^{2}$ from 2010 to 2020. An increase of $11.57 \mathrm{~km}^{2}$ for built-up area and $7.74 \mathrm{~km}^{2}$ for cut block area from 2010 to 2020 were also predicted, and this may be due to the expected escalating industrial activities during the prediction period. In addition, the depleting trend of wetland appears to continue, with another $67.89 \mathrm{~km}^{2}$ of decline from 2010 to 2020. Such wetland depletion needs further examination to 
identify the probable causes.
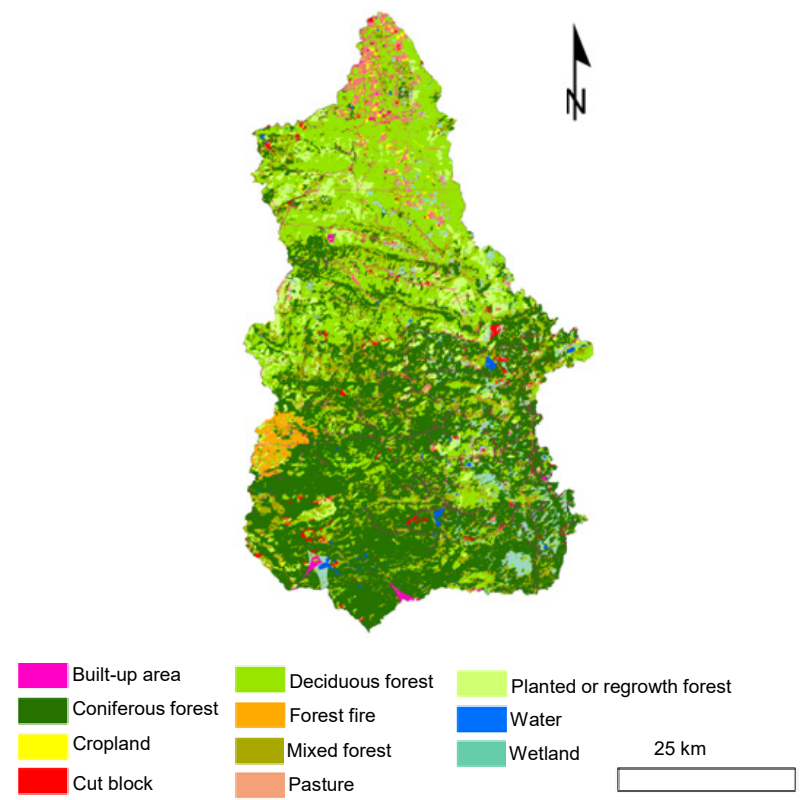

Figure 7. LULC map of 2020 from hard prediction.

\section{Conclusions}

A combination of satellite image classification, GIS analysis, and neural network aided Markov Chain (MC) modeling was used for land use and land cover (LULC) change detection and prediction in the Kiskatinaw River Watershed (KRW) of Canada. A total of 11 LULC types were classified, including cropland, coniferous forest, deciduous forest, mixed forest, planted and regrowth forest, forest cut block, forest fire affected area, pasture, water body, wetland, and built-up area. Landsat TM and ETM+ satellite images of the watershed in three study years (1984, 1999 and 2010) were analyzed using object oriented image classification, with an overall accuracy of $90.45 \%$. The results revealed that the total forest cover accounted for $79.95,85.59$ and $86.28 \%$ of KRW in 1984, 1999 and 2010, respectively. The dynamic variation of different forest types, an increase in built-up area and a significant depletion of wetland were also observed. In particular, the wetland was found to be depleted by $270.92 \mathrm{~km}^{2}$ from 1984 to 2010 in the study watershed of $2836 \mathrm{~km}^{2}$. After image classification, a multi-layer perception neural network aided Markov Chain model was used to predict the change of LULC in 2020. A vulnerability map of LULC change in KRW was generated, and the surface area change of each LULC type was obtained. The modeling prediction indicated a slight variation of LULC types in 2020 , but a wetland depletion of another $67.89 \mathrm{~km}^{2}$ was expected in 2020. This study illustrates that the combination of different tools using Landsat satellite imagery data can provide an effective means for LULC change detection and prediction. A successful integration of highly accurate OOIC based LULC mapping and powerful MC modeling was performed. Although there was insufficient availability of spatial data for this lessstudied watershed, the output of the remote sensing based spa- tial analysis could be adequate to serve as the groundwork for any future research within the study watershed including land use planning, water resource management, forest resource management, and wetland conservations. The research methods are also easily transferrable for LULC change analysis in other watersheds with similar contexts.

Acknowledgements: This research was funded by the City of Dawson Creek, Geoscience BC, British Columbia Oil and Gas Commission, Encana, and BP Canada.

\section{References}

Almeida, C.M., Gleriani, J.M., Castejon, E.F., and Soares-Filho, B.S. (2008). Using neural networks and cellular automata for modeling intra-urban land use dynamics. Int. J. Geogr. Inf. Sci., 22(9), 943-963. https://doi.org/10.1080/13658810701731168

Benito, P., Cuevas, J., Parra, R., Prieto, F., Barrio, J., and Zavala, M. (2010). Land use change in a Mediterranean metropolitan region and its periphery: assessment of conservative policies through CORINE Land Cover data and Markov models. Forest Syst., 19(3), 315-328. https://doi.org/10.5424/fs/2010193-8604

Benz, U.C., Hofmann, P., Willhauck, G., Lingenfelder, I., and Heynen, M. (2004). Multi-resolution, object-oriented fuzzy analysis of remote sensing data for GIS-ready information. ISPRS J. Photogramm. Remote Sens., 58(3-4), 239-258. https://doi.org/10. 1016/ j.isprsjprs.2003.10.002

Blaschke, T. (2010). Object based image analysis for remote sensing. ISPRS J. Photogramm. Remote Sens., 65(1), 2-16. https://doi.org /10.1016/j.isprsjprs.2009.06.004

Blaschke, T., Hay, G.J., Kelly, M., Lang, S., Hofmann, P., Addink, E., and Tiede, D. et al. (2014). Geographic object-based image analysis - towards a new paradigm. ISPRS J. Photogramm. Remote Sens., 87, 180-191. https://doi.org/10.1016/j.isprsjprs.2013.09.014

Cai, Y.P., Huang, G.H., Yang, Z.F., Lin, Q.G. and Tan, Q. (2009a). Community-scale renewable energy systems planning under uncertainty-An interval chance-constrained programming approach. Renew. Sustain. Energ. Rev. 13, 721-735. https://doi.org/10.1016/ j.rser.2008.01.008

Cai, Y.P., Huang, G.H., Yang, Z.F. and Tan, Q. (2009b). Identification of optimal strategies for energy management systems planning under multiple uncertainties. Appl. Energ., 86, 480-495. https:// doi.org/10.1016/j.apenergy.2008.09.025

Chen, J., Mao, Z., Philpot, B., Li, J., and Pan, D. (2013). Detecting changes in high-resolution satellite coastal imagery using an image object detection approach. Int. J. Remote Sens., 34(7), 24542469. https://doi.org/10.1080/01431161.2012.743691

Cohen, W., and Goward, S. (2004). Landsat's role in ecological applications of remote sensing. Bioscience, 54(6), 535-545. https://doi. org/10.1641/0006-3568(2004)054[0535:LRIEAO]2.0.CO;2

Congalton, R., and Green, K. (2009). Assessing the Accuracy of Remotely Sensed Data: Principles and Practices, CRC/Taylor \& Francis, Boca Raton, Florida, USA.

DEUS (Dobson Engineering and Urban Systems Ltd). (2003). Kiskatinaw River Watershed Management Plan, City of Dawson Creek, BC, Canada.

Eastman, J.R. (2012a). Run Transition Sub-Model - Land Change Modeler, IDRISI Help System, IDRISI Selva, Clark University, Worcester, MA, USA.

Eastman, J.R. (2012b). SEGCLASS, IDRISI Help System, IDRISI Selva, Clark University, Worcester, MA, USA.

Fan, Y.R. and Huang, G.H., (2012). A robust two-step method for solving interval linear programming problems within an environ- 
mental management context. J. Environ. Inf., 19, 1-9. https://doi. org/10.3808/jei.201200203

Fraser, R.S., Bahethi, O.P., and Al-Abbas, A.H. (1977). The effect of the atmosphere on the classification of satellite observation to identify surface features. Remote Sens. Environ., 6(3), 229-249. https://doi.org/10.1016/0034-4257(77)90005-0

Frohn, R., Autrey, B., Lane, C., and Reif, M. (2011). Segmentation and object-oriented classification of wetlands in a karst Florida landscape using multi-season Landsat-7 ETM+ imagery. Int. J. Remote Sens., 32(5), 1471-1489. https://doi.org/10.1080/014311 60903559762

Guan, D., Gao, W., Watari, K., and Fukahori, H. (2008). Land use change in Kitakyushu based on landscape ecology and Markov model. J. Geogr. Sci., 18(4), 455-468. https://doi.org/10.1007/s11 442-008-0455-0

Hansen, M., and Loveland, T. (2012). A review of large area monitoring of land cover change using Landsat data. Remote Sens. Environ., 122, 66-74. https://doi.org/10.1016/j.rse.2011.08.024

Iacono, M., Levinson, D., El-Geneidy, A., and Wasfi, R. (2015). A Markov Chain model of land use change. TeMA J. Land Use Mobility Environ., 8(3), 263-276.

Jia, K., Liang, S.L., Liu, J.Y., Li, Q.Z., Wei, X.Q., Yuan, W.P., and Yao, Y.J. (2015). Forest cover changes in the Three-North Shelter Forest Region of China during 1990 to 2005. J. Environ. Inf., doi:10.3808/jei.201400268.https://doi.org/10.3808/jei.201400268

Kawata, Y., Ohtani, A., Kusaka, and T., Ueno, S. (1990). Classification accuracy for the MOS-1 MESSR data before and after the atmospheric correction. IEEE Trans. Geosci. Remote Sens., 28(4), 755-760. https://doi.org/10.1109/TGRS.1990.573015

Li, Y.P., Huang, G.H., and Chen, X., (2011). Planning regional energy system in association with greenhouse gas mitigation under uncertainty. Appl. Energ., 88, 599-611. https://doi.org/10.1016/j.ap energy.2010.07.037

Li, Y.P., Huang, G.H., Huang, Y.F., Zhou, H.D., (2009). A multistage fuzzy-stochastic programming model for supporting sustainable water resources allocation and management. Environ. Model. Soft., 24, 786-797, https://doi.org/10.1016/j.envsoft.2008.11.008

Lin, Y.P., Chu, H.J., Wu, C.F., and Verburg, P.H. (2011). Predictive ability of logistic regression, auto-logistic regression and neural network models in empirical land-use change modeling - a case study. Int. J. Geogr. Inf. Sci., 25(1), 65-87. https://doi.org/10.10 80/13658811003752332

Liu, Y., Guo, Q., and Kelly, M. (2008). A framework of region-based spatial relationships for non-overlapping features and its application in objectbased image analysis. ISPRS J. Photogramm. Remote Sens., 63(4), 461-475. https://doi.org/10.1016/j.isprsjprs. 2008.01.007

Lymburner, L., Beggs, P., and Jacobson, C. (2000). Estimation of canopy-average surface-specific leaf area using Landsat TM data. Photogramm. Eng. Remote Sens., 66(2), 183-191.

Lyons, M.B., Phinn, S.R., and Roelfsema, C.M. (2012). Long term land cover and seagrass mapping using Landsat and object-based image analysis from 1972 to 2010 in the coastal environment of South East Queensland, Australia. ISPRS J. Photogramm. Remote Sens., 71, 34-46. https://doi.org/10.1016/j.isprsjprs.2012. 05.002

MacLean, M., Campbell, M., Maynard, D., Ducey, M., and Congalton, R. (2013). Requirements for labeling forest polygons in an object-based image analysis classification. Int. J. Remote Sens., 34(7), 2531-2547. https://doi.org/10.1080/01431161.2012.747017

Martha, T.R., Kerle, N., Van Westen, C.J., Jetten, V., and Kumar, K.V. (2011). Segment optimization and data-driven thresholding for knowledge-based landslide detection by object-based image analysis. IEEE T. Geosci. Remote Sens., 49(12), 4928-4943. https://doi.org/10.1109/TGRS.2011.2151866
Mas, J.F., Kolb, M., Paegelow, M., Olmedo, M.T., and Houet, T. (2014). Inductive pattern-based land use/cover change models: A comparison of four software packages. Environ. Model. Software, 51, 94-111. https://doi.org/10.1016/j.envsoft.2013.09.010

Monserud, R., and Leemans, R. (1992). Comparing global vegetation maps with Kappa statistic. Ecol. Model., 62(4), 275-293. https:// doi.org/10.1016/0304-3800(92)90003-W

Myint, S., Gober, P., Brazel, A., Grossman-Clarke, S., and Weng, Q. (2011). Per-pixel vs. object-based classification of urban land cover extraction using high spatial resolution imagery. Remote Sens. Environ., 115(5), 1145-1161. https://doi.org/10.1016/j.rse. 2010.12.017

Olofsson, P., Foody, G.M., Herold, M., Stehman, S.V., Woodcock, C.E., and Wulder, M.A. (2014). Good practices for estimating area and assessing accuracy of land change. Remote Sens. Environ., 148, 42-57. https://doi.org/10.1016/j.rse.2014.02.015

Redoux, J., and Defourny, P. (2007). A quantitative assessment of boundaries in automated forest stand delineation using high-resolution imagery. Remote Sens. Environ., 110(4), 468-475. https:// doi.org/10.1016/j.rse.2007.02.031

Revesty, M. (2011). The assessment and predicting of land use changes to urban area using multi-temporal satellite imagery and GIS: A case study on Zanjan, Iran (1984-2011). J. Geogr. Inf. Syst., 3, 298-305. https://doi.org/10.4236/jgis.2011.34026

Rimal, B. (2011). Application of remote sensing and GIS, land use/land cover change in Kathmandu Metropolitan City, Nepal. J. Theor. Appl. Inf. Technol., 23(2), 80-86.

Robertson, L.D., and King, D. (2011). Comparison of pixel- and object-based classification in land cover change mapping. Int. J. Remote Sens., 32, 1505-1529. https://doi.org/10.1080/014311609 03571791

Song, C., Woodcock, C.E., Seto, K.C., Lenney, M.P., and Macomber, S. A. (2001). Classification and change detection using Landsat TM data: when and how to correct atmospheric effects? Remote Sens. Environ., 75(2), 230-244. https://doi.org/10.1016/s0034-42 57(00)00169-3

Strigul, N., Florescu, I., Welden, A.R., and Michalczewski, F. (2012). Modeling of forest stand dynamics using Markov chains. Environ. Model Software., 31, 64-75. https://doi.org/10.1016/j.envsoft.201 1.12 .004

Tong, S.T.Y., Sun, Y., and Yang, J. (2012). Generating a future land use change scenario with a modified population-coupled Markov Cellular Automata model. J. Environ. Inf., 19(2), 108-119.

Verburg, P.H., Kok, K., Pontius Jr, R.G., and Veldkamp, A. (2006). Modeling land-use and land-cover change, Land-Use and LandCover Change. Springer Berlin Heidelberg, pp. 117-135. https:// doi.org/10.1007/3-540-32202-7 5

Verstegen, J.A., Karssenberg, D., Hilst, F., and Faaij, A.P.C. (2014). Identifying a land use change cellular automaton by Bayesian data assimilation. Environ. Model. Software, 53, 121-136. https:// doi.org/10.1016/j.envsoft.2013.11.009

Vieira, M., Formaggio, A., Renno, C., Atzberger, C., Aguiar, D., and Mello, M. (2012). Object based image analysis and data mining applied to a remotely sensed Landsat time-series to map sugarcane over large areas. Remote Sens. Environ., 123, 553-562. https://doi.org/10.1016/j.rse.2012.04.011

Weinzettel, J., Hertwich, E., Peters, G., Steen-Olsen, K., and Galli, A. (2013). Affluence drives the global displacement of land use. Global Environ. Change, 23(2), 433-438. https://doi.org/10.1016/ j.gloenvcha.2012.12.010

Zhang, Y., Lu, D., Yang, B., Sun, C., and Sun, M. (2011). Coastal wetland vegetation classification with a Landsat Thematic Mapper image. Int. J. Remote Sens., 32(2), 545-561. https://doi.org/10. 1080/01431160903475241 